\title{
ORIGINAL ARTICLE \\ Relationship between function, strength and electromyography of upper extremities of persons with tetraplegia
}

\author{
VM de Vargas Ferreira ${ }^{1}, \mathrm{R}$ Varoto $^{2}, \hat{E} W$ Azevedo Cacho ${ }^{3}$ and A Cliquet $\mathrm{Jr}^{1}$
}

Study design: Cross-sectional.

Objective: To analyze the relationships between functional tests, arm strength and root mean square of surface electromyography (EMG).

Setting: Sao Paulo, Brazil.

Methods: Twenty-four individuals with chronic tetraplegia participated. Upper extremity motor score (UEMS), functional independence measure (FIM) motor score, spinal cord independence measure III and capabilities of upper extremity (CUE) were performed. Muscle strength of the right elbow flexors-extensors was assessed using dynamometry and manual muscle test (MMT) and EMG of right biceps and triceps brachii were performed. Spearman's rank correlation coefficients and Mann-Whitney's U-test were used.

Results: Functional tests and UEMS correlated strongly among them. UEMS highly correlated with triceps dynamometry and EMG. The dynamometry showed a very high correlation with MMT on the extensor group and a moderate correlation with flexor group. Triceps EMG showed moderate correlation with FIM and CUE. High correlations between triceps EMG and elbow extensors dynamometry and MMT were observed. A significant better performance on functional tests was observed on lower ASIA motor levels. The low-tetraplegia group showed a significant higher score on triceps EMG and dynamometry.

Conclusion: Arm strength and EMG seem to be related to functional capabilities and independence in chronic tetraplegia. Spinal Cord (2012) 50, 28-32; doi:10.1038/sc.2011.95; published online 30 August 2011

Keywords: tetraplegia; arm; assessment; strength; dynamometry; EMG

\section{INTRODUCTION}

Persons with tetraplegia have severe function loss due to the lack of motor control and strength. To overcome these impairments, they often use compensatory strategies to perform activities of daily life (ADL). ${ }^{1}$ Several instruments are used by clinicians and researchers to quantify and analyze the relations between independence, functional capabilities and strength. ${ }^{2}$

The ASIA classification is used to perform neurological tests and to determine the motor level through the strength manual muscle test (MMT). To evaluate disability the functional independence measure (FIM) and spinal cord independence measure III (SCIM) are generally used in spinal cord injury (SCI). ${ }^{3}$ The capabilities of upper extremity (CUE) is a questionnaire specific to measure the upper extremity impairment of individuals with tetraplegia. To analyze the strength deficit, MMT is the measure most utilized for SCI; however, dynamometry has been shown to be more sensitive than MMT. ${ }^{4,5}$

Electromyography (EMG) is commonly used to analyze muscle recruitment during several activities. ${ }^{6}$ There are few studies that used the EMG as a predictor of strength in acute and subacute tetraplegia. ${ }^{7,8,9}$ Therefore, the purpose of the present study was to analyze the correlations between functional tests, strength and EMG of the upper limb of persons with chronic tetraplegia.

\section{PATIENTS AND METHODS}

\section{Participants}

Twenty-four individuals with tetraplegia (23 males and one female) selected from of the University Hospital were included in this study. The participants presented motor level between C4 and C8, mean (s.d.) age of 34.6 (10.3) years, range from 21-61 years, body mass index of $22.3(2.94) \mathrm{kg} \mathrm{m}^{-2}$, and chronic traumatic lesion, for mean 7.6 (4.9) years. Inclusion criteria consisted of SCI following traumatic lesion, at least 2 years of SCI, neurological level between $\mathrm{C} 4$ and T1 and age over 18 years. Exclusion criteria were as follows: did not have sufficient comprehension to understand the questionnaires, had previous neurological or degenerative disease, upper extremity musculoskeletal disorders and tendon transfers surgery. The study was approved by the local ethics committee.

\section{Procedures}

The clinical assessment of level and severity of injury was performed by the same clinician according to ASIA. ${ }^{10}$ The upper extremity motor score (UEMS) was calculated by summing the C5-T1 muscle groups MMT, at right and left upper extremities. Despite standardized supine position, the test was executed with the subjects sitting on their own wheelchair with trunk or arm stabilization, if necessary. The scores for elbow flexors and extensors of the right arm were used separately for strength analysis.

Functional outcome was performed through the following tools: FIM motor score, SCIM and CUE. The FIM motor score comprehends four domains of ADL, with a total of 13 items scored in a range of one to seven. ${ }^{11}$ The SCIM has

\footnotetext{
${ }^{1}$ Department of Orthopedics and Traumatology, Faculty of Medical Sciences, UNICAMP, State University of Campinas, Campinas, Brazil; ${ }^{2}$ Department of Electrical Engineering, Engineering School of Sao Carlos, University of Sao Paulo, Sao Carlos, Brazil and ${ }^{3}$ Faculty of Health Sciences at Trairi, Federal University of Rio Grande do Norte, Santa Cruz, Brazil Correspondence: VM de Vargas Ferreira, Department of Orthopedics and Traumatology, Faculty of Medical Sciences, UNICAMP, State University of Campinas, Caixa Postal 6111, Campinas, Sao Paulo, Brazil.

E-mail: vavargas@fcm.unicamp.br

Received 24 March 2011; revised 9 June 2011; accepted 19 July 2011; published online 30 August 2011
} 

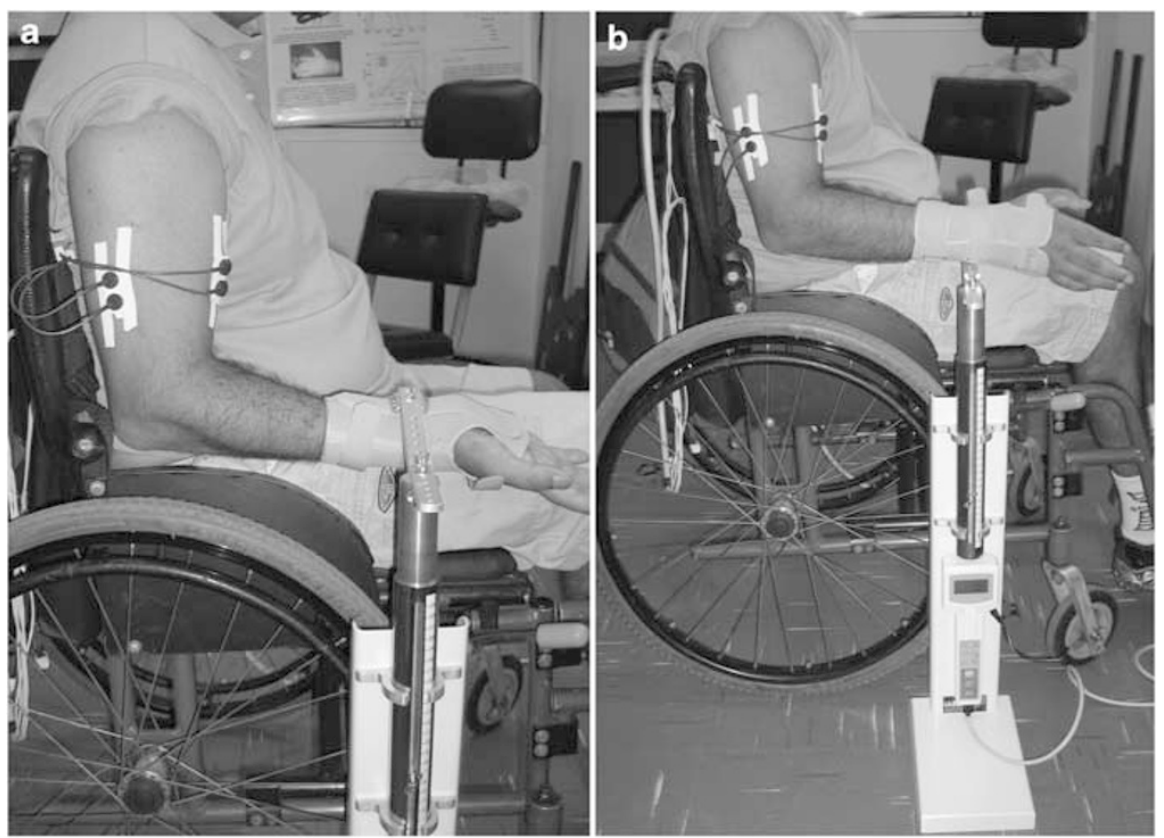

Figure 1 Dynamometry and EMG assessment of elbow flexors (a) and extensors (b) of the right arm.

19 tasks divided in four areas: self-care (scored 0-20), respiration and sphincter management $(0-40)$, mobility in room and toilet $(0-10)$, mobility indoors and outdoors $(0-30) .{ }^{12}$ The CUE is a questionnaire developed to assess upper extremities performance in tetraplegia. The individual assigns a score from one to seven for 32 items. ${ }^{13}$ All surveys were conducted by the same physiotherapist in a maximum of 23 days of difference between them.

An electronic DFS-100 dynamometer (Shimpo Instruments, Itasca, IL, USA) was adapted to measure maximal isometric strength of elbow flexors and extensors on the right arm. A LabVIEW DAQCard-6024E (National Instruments, Austin, TX, USA) was used for data acquisition using software for dynamometry and EMG synchronism. The subject was sitting in his or her own wheelchair, with the shoulder in a neutral position and the forearm at $90^{\circ}$. For the assessment of elbow flexors, the wrist was positioned in a supine position, and for elbow extensors in neutral position (Figure 1). The participant was instructed to perform a maximal contraction against the dynamometer shaft for $5 \mathrm{~s}$ with a rest period of $10 s(n=9)$. The evaluator stabilized the dynamometer to ensure an isometric test. The mean value of the nine trials was used as the dynamometric data.

EMG was performed in synchronism with dynamometry, using a Noraxon Myosystem 2000 (Noraxon U.S.A. Inc., Scottsdale, AZ, USA), with a CIO PCM-DAS16S/12 single-ended analog-digital converter (ComputerBoards Inc., Middleboro, MA, USA) of 12 bits resolution, data acquisition board of 2000 samples per second, $100 \mathrm{~dB}$ of common mode rejection ratio at $60 \mathrm{~Hz}$, differential input impedance of $10 \mathrm{Mohms}$ and input noise voltage of $1 \mathrm{uV}$ root mean square. A $60 \mathrm{~Hz}$ notch filter was used with 100th order high-pass and low-pass FIR filters, cut-off frequencies of $20 \mathrm{~Hz}$ and $500 \mathrm{~Hz}$, respectively. Bipolar, self adhesive and disposable $\mathrm{Ag} / \mathrm{AgCl}$ surface electrodes, with an interelectrode distance of $20 \mathrm{~mm}$, were attached after alcohol applied to cleanse skin. Right biceps brachii and lateral head of right triceps brachii were located by palpation and by muscle function test, and the electrodes were attached. ${ }^{14}$ The reference electrode was positioned on the $\mathrm{C} 7$ spinous process.

\section{Data analysis}

The myoelectric activity was obtained in root mean square and it was used as the average value of the nine trials. Spearman's rank correlation coefficients ( $r$ s) were used to determine the strength of association between UEMS, FIM, SCIM, CUE, MMT, dynamometry and EMG. For the EMG and dynamometric analysis, the participants were divided in high tetraplegia (motor level from C5 to C6, $n=8)$ and low tetraplegia $(\mathrm{C} 7-\mathrm{C} 8, n=5)$, and to identify differences in functional tests, the C5 $(n=8)$, C6 $(n=6)$ and C7 $(n=4)$ ASIA motor levels were analyzed, the non-parametric Mann-Whitney's $U$-test was used. Data were statistically analyzed with Matlab 7.0 (Mathworks, Natick, MA, USA). Significance was fixed at the 0.05 . The strength of the relationship was adopted as follows: $0.00-0.25$, little if any; $0.26-0.49$, low; $0.50-0.69$, moderate; 0.70 0.89 , high; $0.90-1.00$, very high. ${ }^{15}$

\section{RESULTS}

Of the 24 patients analyzed, nine did not undergo the dynamometry and EMG, and other three participants were not interviewed, because they could not attend the evaluation days, which two of them did not perform the MMT.

Demographic and clinical characteristics can be found in Table 1. Only one individual had motor function below the neurological level, with MMT no greater than 3, classified as ASIA C; five patients had different motor levels for right-left sides (C6-C5, C6-C5, C7-T1, C8$\mathrm{T} 1, \mathrm{~T} 1-\mathrm{C} 8$ ), and one patient was diagnosed with syringomyelia. The correlations between each variable are presented in Table 2 .

The tests (FIM, SCIM and CUE) presented high to very high correlation with UEMS, and between themselves. Dynamometry of elbow flexors showed a moderate correlation with the other variables (functional tests, right UEMS, biceps EMG and MMT); furthermore, the elbow extensors dynamometry correlated highly to very highly with functional tests, right UEMS, triceps EMG and MMT. Triceps EMG had moderate correlations with functional tests and high correlation with right UEMS, dynamometry and MMT; however, the biceps EMG only showed significant relationship with the dynamometry.

Differences between the ASIA motor levels are shown in the Figures 2-6. The C5 level showed a significant lower score on all functional tests, compared with the C6 and C7 levels. The triceps EMG and dynamometry were significantly higher on the lower group. Non-significant differences between the groups were seen on biceps EMG and dynamometry.

\section{DISCUSSION}

The functional tests present great correlation among them and with the UEMS. ${ }^{12,13,16,17}$ In the present work, those tests were able to detect differences in performance between the tetraplegia motor levels, 
although among the C6 and C7 levels it was not significant. These findings can indicate that the extensors of the wrist have an important role on motor functional and independence of persons with tetraplegia, also that triceps brachii paralysis does not seem to be a limiting factor to execute $\mathrm{ADL}$, as patients with $\mathrm{C} 6$ motor level are used to do external rotation of the shoulder to extend the elbow. ${ }^{1}$

Table 1 Demographic and clinical data of subjects $(n=24)$

\begin{tabular}{|c|c|c|}
\hline Characteristic & $\mathrm{N}$ & $\%$ \\
\hline \multicolumn{3}{|l|}{ Etiology } \\
\hline Vehicular & 10 & 41,7 \\
\hline Diving & 8 & 33,3 \\
\hline Violence & 5 & 20,8 \\
\hline Sports & 1 & 4,2 \\
\hline \multicolumn{3}{|l|}{ ASIA grade } \\
\hline A & 20 & 83,3 \\
\hline B & 3 & 12,5 \\
\hline C & 1 & 4,2 \\
\hline \multicolumn{3}{|c|}{ Neurological level } \\
\hline C4 & 11 & 45,8 \\
\hline $\mathrm{C} 5$ & 6 & 25 \\
\hline C6 & 6 & 25 \\
\hline $\mathrm{C7}$ & 0 & 0 \\
\hline C8 & 1 & 4,2 \\
\hline \multicolumn{3}{|l|}{ Motor level } \\
\hline C4 & 2 & 8,3 \\
\hline $\mathrm{C} 5$ & 9 & 37,5 \\
\hline C6 & 7 & 29,2 \\
\hline $\mathrm{C7}$ & 4 & 16,7 \\
\hline C8 & 2 & 8,3 \\
\hline \multicolumn{3}{|c|}{ Right motor level } \\
\hline $\mathrm{C} 4$ & 2 & 8,3 \\
\hline C5 & 7 & 29,2 \\
\hline C6 & 9 & 37,5 \\
\hline $\mathrm{C7}$ & 4 & 16,7 \\
\hline C8 & 1 & 4,2 \\
\hline T1 & 1 & 4,2 \\
\hline
\end{tabular}

Muscle strength of the upper limb can be a good predictor of functional capabilities in tetraplegia. ${ }^{16,18,19}$ In this work, elbow extension strength presented a better correlation with functional tests than

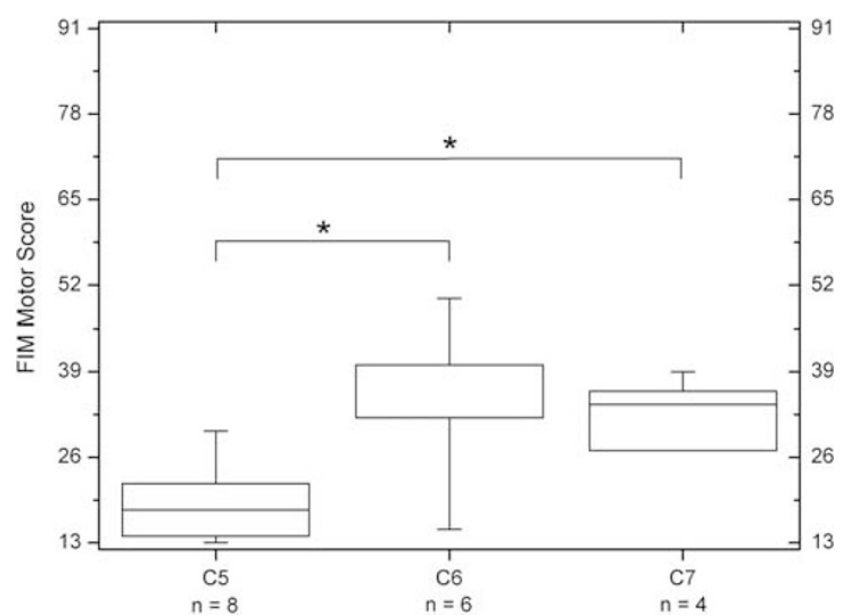

Figure 2 FIM motor scores for C5, C6 and C7 tetraplegia motor levels. *Significant difference between tetraplegia levels $(P<0.01)$.

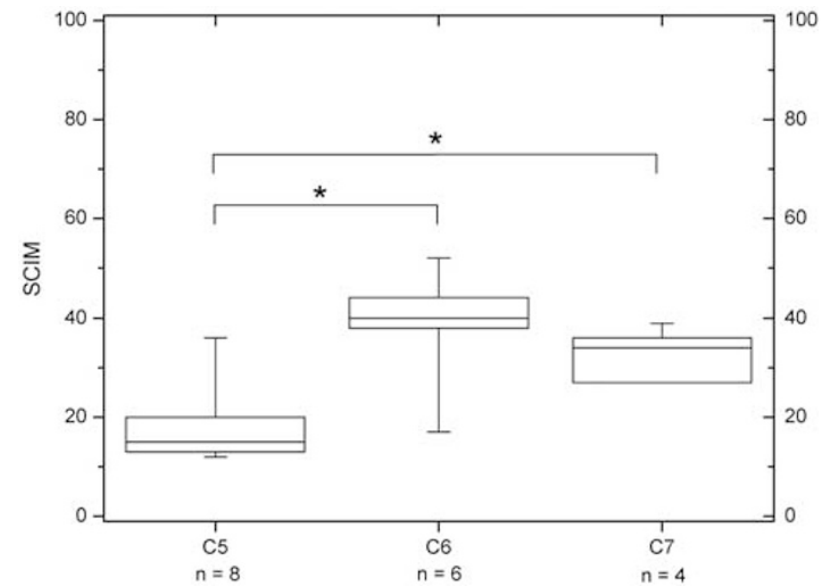

Figure 3 SCIM scores for C5, C6 and C7 tetraplegia motor levels. * Significant difference between tetraplegia levels $(P \leqslant 0.01)$.

Table 2 Spearman correlation coefficients

\begin{tabular}{l|cccccccccc}
\hline Methods & FIM & SCIM & CUE & UEMS & RUEMS & fl MMT & ext MMT & fl dyna & ext dyna & EMGb \\
\hline SCIM & $0.91 \#$ & & & & & & & & & \\
CUE & $0.83 \#$ & $0.81 \#$ & & & & & & & & \\
UEMS & $0.82 \#$ & $0.79 \#$ & $0.86 \#$ & & & & & & & \\
RUEMS & $0.78 \#$ & $0.75 \#$ & $0.84 \#$ & $0.98 \#$ & & & & & & \\
fl MMT & NS & NS & $0.40^{*}$ & $0.61 \#$ & $0.69 \#$ & & & & \\
ext MMT & $0.68 \#$ & $0.61+$ & $0.74 \#$ & $0.88 \#$ & $0.89 \#$ & $0.45^{*}$ & & & \\
fl dyna & $0.68+$ & $0.66+$ & $0.63+$ & $0.57^{*}$ & $0.67+$ & $0.65+$ & NS & & & \\
ext dyna & $0.85 \#$ & $0.67+$ & $0.80 \#$ & $0.86 \#$ & $0.91 \#$ & $0.69+$ & $0.90 \#$ & $0.50^{*}$ & & \\
EMGb & NS & NS & NS & NS & NS & NS & NS & $0.67+$ & NS & \\
EMGt & $0.60^{*}$ & NS & $0.52^{*}$ & $0.77 \#$ & $0.84 \#$ & $0.86 \#$ & $0.83 \#$ & $0.47^{*}$ & $0.82 \#$ & NS \\
\hline
\end{tabular}

Correlation strength: $\square$ Very high; $\square$ High; $\square$ Moderate; $\square$ Low;

Abbreviations: CUE, capabilities of upper extremity; EMG, electromyography; EMGb, right biceps EMG; EMGt, rigth triceps EMG; ext dyna, rigth elbow extensors dynamometry; ext MMT, rigth elbow extensors MMT; FIM, functional independence measure motor score; fl dyna, rigth elbow flexors dynamometry; fl MMT, rigth elbow flexors MMT; MMT, manual muscle test; NS, not significant; RUEMS, right UEMS; SCIM, spinal cord independence measure III; UEMS, upper extremity motor score.

$*(P<0.05) \cdot+(P<0.01) ; \#(P<0.001)$; NS $(P>0.05)$ 


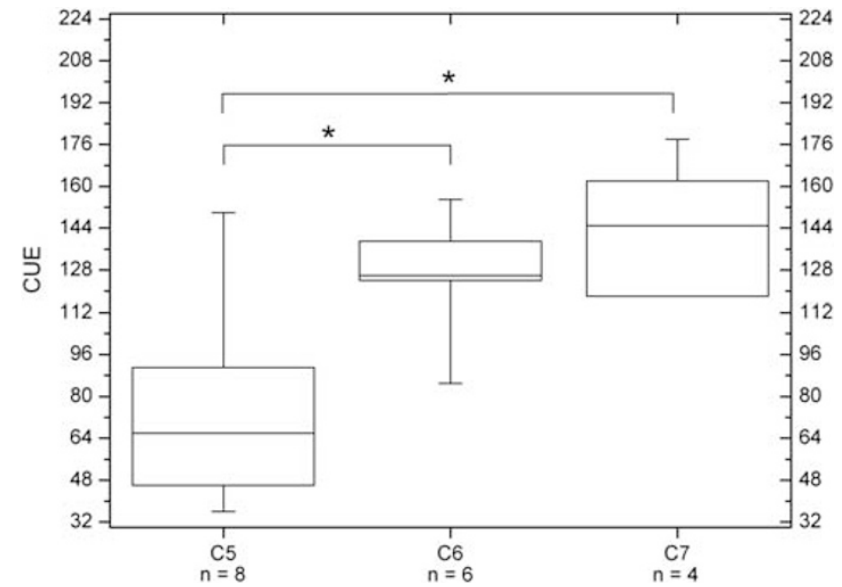

Figure 4 CUE scores for $\mathrm{C} 5, \mathrm{C} 6$ and $\mathrm{C} 7$ tetraplegia motor levels. *Significant difference between tetraplegia levels $(P \leqslant 0.02)$.

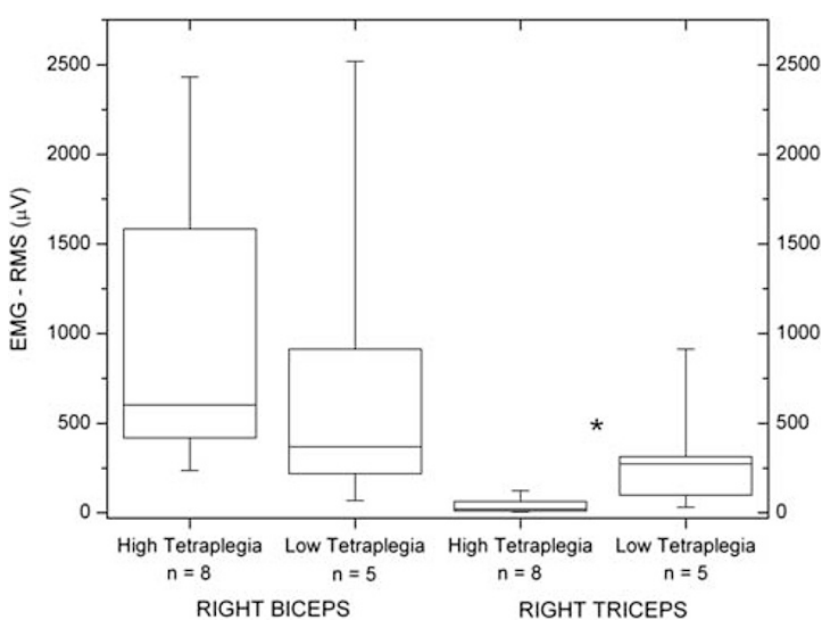

Figure 5 Biceps and triceps EMG values of the right arm for high (C5-C6) and low (C7-C8) tetraplegia. ${ }^{*}$ Significant difference between tetraplegia levels $(P=0.01)$.

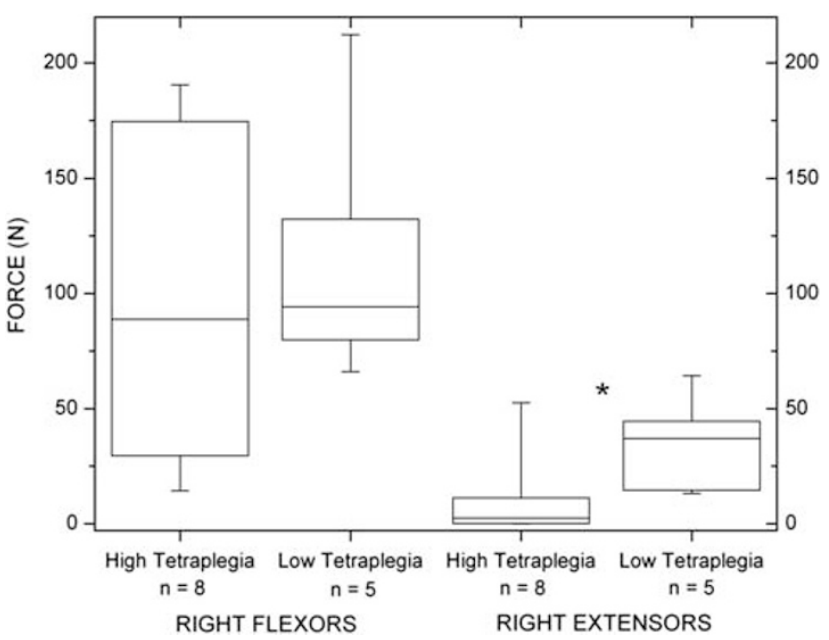

Figure 6 Flexors and extensors dynamometry values of the right arm for high (C5-C6) and low (C7-C8) tetraplegia. *Significant difference between tetraplegia levels $(P=0.02)$. the elbow flexion. This finding corroborates with previous work that showed a high correlation between SCIM self-care domain and elbow extension MMT, and a low correlation with elbow flexion. ${ }^{18}$ In contrast, in another study, elbow flexion was related more to FIM motor tasks than elbow extension. ${ }^{19}$

As expected, a positive correlation between the strength values measured by MMT and dynamometry for elbow flexors and extensors muscle groups was observed. The correlation between dynamometric and MMT strength of elbow extensors was significantly higher than elbow flexors. These could be explained by the limited reliability and responsiveness of MMT grades greater than $3 .^{4}$ In our sample, 13 participants attended both strength analysis and only three presented MMT grade 3 or less for elbow flexor muscle group, compared with 10 of 13 for elbow extensor.

Despite the international use of MMT for strength measurement, this tool has been reported not to be sufficiently sensitive to assess muscle strength and to have limited accuracy to detect changes. Dynamometry has been demonstrated to be more accurate than MMT $^{5,6,20}$ and was also reported to be a better indicator of selfcare independence. ${ }^{21}$ In this work, only the elbow flexor strength measured by dynamometry related better to the functional tests than MMT. Analysis of a larger sample and strength assessment of several muscular groups with dynamometry and MMT would provide a better understanding of the relationship between different methods of strength assessment and functional tasks for each muscular group.

EMG testing has been used in SCI to analyze muscle activity pattern during ADL. ${ }^{6}$ To date, we are unaware of EMG analysis in tetraplegia that had compared the muscle activation with functional tests. The present results showed that triceps EMG moderately correlated with functional tests and highly correlated with UEMS; however, biceps EMG did not present a significant correlation with these tests.

The triceps EMG also presented a high correlation with triceps strength measured by MMT and dynamometry, though biceps EMG only correlated with the dynamometric evaluation. In previous works, EMG recruitment has been shown to be an indication of voluntary strength through association with biceps and triceps MMT scores ${ }^{8}$ and triceps dynamometry. ${ }^{7}$ However, we should be careful on the interpretation of relationship between EMG and strength considering the intrinsic issues inherent from EMG, as crosstalk and stability of the motor unit activation pattern. ${ }^{22}$

A potential cause for discrepancy between biceps and triceps EMG correlations could be the major number of participants with triceps brachii paralysis, resulting in a minor variability of the EMG. Other factor that must be considered is spontaneous involuntary EMG, as seen in spasticity, which increases the EMG magnitude.

In conclusion, muscle strength measured with MMT and dynamometry was positively related to functional tests. EMG has been shown to be related to muscle strength in persons with chronic SCI. Triceps EMG was also significantly related to the functional analysis.

EMG appears to be a useful tool and could be used as an indication of function and strength in chronic tetraplegia. More studies are needed to analyze if the EMG and dynamometry are more sensitive to the discrete progress that chronic patients present that could not be observed with other tools.

\section{CONFLICT OF INTEREST}

The authors declare no conflict of interest.

\section{ACKNOWLEDGEMENTS}

This work was supported by the State of São Paulo Foundation for Research FAPESP. 
1 Hoffman G, Laffont I, Hanneton S, Roby-Brami A. How to extend the elbow with a weak or paralyzed triceps: control of arm kinematics for aiming in C6-C7 quadriplegic patients. Neuroscience 2006; 139: 749-765.

2 van Tuijl JH, Janssen-Potten YJM, Seelen HAM. Evaluation of upper extremity motor function tests in tetraplegics. Spinal Cord 2002; 40: 51-64.

3 Steeves JD, Fawcett JW, Curt A, Coleman WP, Tuszynski MH, Lammertse D et al. Guidelines for the conduct of clinical trials for spinal cord injury (SCI) as developed by the ICCP panel: clinical trial outcome measures. Spinal Cord 2007; 45: 206-221.

4 Noreau L, Vachon J. Comparison of three methods to assess muscular strength in individuals with spinal cord injury. Spinal Cord 1998; 36: 716-723.

5 Sisto SA, Dyson-Hudson T. Dynamometry testing in spinal cord injury. J Rehabil Res Dev 2007; 44: 123-136.

6 Mulcahey MJ, Hutchinson D, Kozin S. Assessment of upper limb in tetraplegia: considerations in evaluation and outcomes research. J Rehabil Res Dev 2007; 44: 91-102.

7 Thomas CK, Tucker ME, Bigland-Ritchie B. Voluntary muscle weakness and coactivation after chronic cervical spinal cord injury. J Neurotrauma 1998; 15: 149-161.

8 Calancie B, Molano MR, Broton JG, Bean JA, Alexeeva N. Relationship between EMG and muscle force after spinal cord injury. J Spinal Cord Med 2001; 24: 19-25.

9 Calancie B, Molano MR, Broton JG. EMG for assessing the recovery of voluntary movement after acute spinal cord injury in man. Clin Neurophysiol 2004; 115: 1748-1759.

10 Marino RJ, Barros T, Biering-Sorensen F, Burns SP, Donovan WH, Graves DE et al. International standards for neurological classification of spinal cord injury. J Spinal Cord Med 2003; 26: S50-S56.

11 Riberto M, Miyazaki MH, Jucá SSH, Sakamoto H, Pinto PPN, Battistella LR. Validation of the Brazilian version of Functional Independence Measure. Acta Fisiatr 2004; 11: $72-76$
12 Itzkovich M, Gelernter I, Biering-Sorensen F, Weeks C, Laramee MT, Craven BC et al. The Spinal Cord Independence Measure (SCIM) version III: reliability and validity in a multi-center international study. Disabil Rehabil 2007; 29: 1926-1933.

13 Marino RJ, Shea JA, Stineman MG. The capabilities of upper Extremity instrument: reliability and validity of a measure of functional limitation in tetraplegia. Arch Phys Rehabil 1998; 79: 1512-1521.

14 Hermens HJ, Freriks B, Disselhorst-Klug C, Rau G. Development of recommendations for SEMG sensors and sensor placement procedures. J Electromyogr Kinesiol 2000; 10: 361-374.

15 Munro BH. Correlation. In: Statistical Methods for Health Care Research. 5th edn. Lippincott Williams \& Williams: Philadelphia, 2004 pp 239-256.

16 Fujiwara T, Hara Y, Akaboshi K, Chino N. Relationship between shoulder muscle strength and functional independence measure (FIM) score among C6 tetraplegics. Spinal Cord 1999; 37: 58-61.

17 Marino RJ, Graves DE. Metric properties of the ASIA motor score: subscales improve correlation with functional activities. Arch Phys Med Rehabil 2004; 85: 1804-1810.

18 Rudhe C, van Hedel HJA. Upper extremity function in persons with tetraplegia: relationships between strength, capacity, and the spinal cord independence measure. Neurorehabil Neural Repair 2009; 23: 413-421.

19 Beninato M, O'Kane KS, Sullivan PE. Relationship between motor FIM and muscle strength in lower cervical-level spinal cord injuries. Spinal Cord 2004; 42: 533-540.

20 Drolet M, Noreau L, Vachon J, Moffet H. Muscle strength changes as measured by dynamometry following functional rehabilitation in individuals with spinal cord injury. Arch Phys Med Rehabil 1999; 80: 791-800.

21 Marciello MA, Herbison GJ, Ditunno JF, Marino RJ, Cohen ME. Wrist strength measured by myometry as an indicator of functional independence. J Neurotrauma 1995; 12 : 99-106.

22 De Luca CJ. The use of surface electromyography in biomechanics. J App/ Biomech 1997; 13: 135-163. 